\title{
A new alphabet for COPD care
}

\author{
Edward Kerwin
}

Affiliation: Clinical Research Institute, Medford, OR, USA.

Correspondence: Edward Kerwin, Clinical Research Institute of Southern Oregon, 3860 Crater Lake Avenue, Medford, OR, 97504, USA. E-mail: ekerwinacriresearch.com

0 @ERSpublications

Combination bronchodilators improve air flow in COPD patients in trials: a defined group may benefit from ICS/LABAs http://ow.ly/ophD302Qm5i

For 6 years, chronic obstructive pulmonary disease (COPD) specialists have struggled to discern deeper meanings in the 2011 Global Initiative for Chronic Obstructive Pulmonary Disease (GOLD) A, B, C and D classification scheme [1, 2]. Now new letters, LAMA/LABA, ICS/LABA, LAMA, LABA, MABA, ICS/LAMA/ LABA, SABA/SAMA (MAMMA MIA!) are dancing across the pages of COPD pharmacotherapy [3].

Inhaled corticosteroid (ICS)/long-acting beta-agonist (LABA) combinations such as salmeterol/fluticasone propionate (SFC) have played a fundamental role in COPD care since at least 2007, when the TORCH study demonstrated a trend towards reduced mortality compared with placebo [4]. ICS/LABAs remain ubiquitous COPD treatments. They are highly established and yield patient-reported outcome (PRO) benefits similar to other dual combinations. No head-to-head studies have yet found mortality benefits for combination dual bronchodilators (long-acting muscarinic antagonist/long-acting beta-agonist (LAMA/ LABAs)), such as indacaterol/glycopyrrolate, umeclidinium/vilanterol, tiotropium/olodaterol, aclidinium/ formoterol or the newest approved drug glycopyrrolate/formoterol metered dose inhaler, compared with ICS/LABAs. ICS/LABAs remain the paradigmatic treatment for asthma, suppressing T-helper (Th) type 2 cell nuclear transcription factors which orchestrate most asthmatic inflammation. Generic ICS/LABAs promise to further expand therapeutic options and potentially reduce healthcare costs. Primary care physicians baffled by discerning COPD from asthma often reach for ICS/LABAs as proven, cost-effective, multidimensional maintenance anti-inflammatory treatment for both COPD and asthma obstructive lung diseases.

Yet, head-to-head studies of newer LAMA/LABAs against a leading ICS/LABA, SFC, have shown LABA/ LAMA combinations are frankly better than ICS/LABAs in moderate, exacerbation-free COPD patients [5-7], in more severe GOLD B and D patients [8], and most recently in a moderate exacerbation-prone population with one or more exacerbation annually [9].

These head-to-head COPD studies ranged from a 6-week crossover study (ENERGITO) [7], to 12 weeks [6], to 26 weeks (ILLUMINATE and LANTERN) [5, 8], and to 52 weeks in the exacerbation study (FLAME) [9]. In each head-to-head trial, the LAMA/LABAs showed significant superiority by $74-155 \mathrm{~mL}$ over ICS/LABA (SFC) in daytime airflow measures such as area under the forced expiratory volume in $1 \mathrm{~s}$ curve (AUC FEV1) 0-12 h, peak FEV1, 0-3 h AUC FEV1 or $24 \mathrm{~h} \mathrm{AUC} \mathrm{FEV1.} \mathrm{Trough} \mathrm{FEV1} \mathrm{also} \mathrm{improved} \mathrm{with} \mathrm{LAMA/}$ LABAs versus ICS/LABA (by 58-103 mL) [5-9], while hyperinflation measured by inspiratory capacity (IC) or forced vital capacity (FVC) similarly improved [7,9]. Quite importantly, in a mildly exacerbating COPD population ( $\geqslant 1$ exacerbation annually), rates of "all", "moderate-to-severe" and "time to first moderate-to-severe" COPD exacerbation all improved by 11-17\% with indacaterol/glycopyrrolate versus SFC [9]. Even patients on prior ICS, patients with two or more exacerbations in the prior year and patients with higher blood eosinophils levels (over 2\%) fared marginally better with the LAMA/LABA versus the ICS/ LABA over the 52-week FLAME head-to-head study. However, PROs, such as the Transitional Dyspnoea Index (TDI), COPD Assessment Test (CAT) and health status measures like the Saint George's Respiratory Questionnaire (SGRQ), as well as adverse event rates and mortality outcomes have come out approximately

Received: June 222016 | Accepted: June 232016

Conflict of interest: Disclosures can be found alongside this article at erj.ersjournals.com

Copyright $\odot$ ERS 2016 
equal, with very few statistical or clinically significant differences in head-to-head studies between LAMA/LABAs versus ICS/LABAs. An ongoing Cochrane meta-analysis may further clarify these head-to-head comparisons [10].

In this issue of the European Respiratory Journal, VogELMEIER et al. [11] add helpful information on another twice daily LAMA/LABA, aclidinium $400 \mu \mathrm{g} /$ formoterol $12 \mu \mathrm{g}$ (ACL/FOR), reporting efficacy and safety results of the AFFIRM trial, a 24-week, double-blind, double-dummy, comparison of twice daily ACL/FOR versus twice daily SFC in moderate-to-severe COPD patients with CAT $>10$ (GOLD classes B and D), with or without exacerbations in the prior year [11]. This study employed a "real world" randomisation design without washing out background bronchodilators.

Like other head-to-head trials of LAMA/LABAs versus ICS/LABAs, the AFFIRM trial again found significant airway benefits of $93 \mathrm{~mL}$ favouring ACL/FOR for peak FEV 1 at 24 weeks (and similar improvements in 0-3 h AUC FEV1). Interestingly, two severity subgroups that might denote higher inflammation risk still fared better with LAMA/LABA. Patients on prior ICS improved their peak FEV 1 by $122 \mathrm{~mL}$ versus $76 \mathrm{~mL}$ for the no prior ICS group, while patients with one or more exacerbation in the prior year (32-33\%) improved by $113 \mathrm{~mL}$ versus $84 \mathrm{~mL}$. It seems the very patients who might be targeted for ICS based on prior ICS (a potential marker of labile COPD) or prior exacerbations acquired better airflow outcomes with the LAMA/LABA treatment (ACL/FOR).

Safety outcomes in the study of VogelmeIER et al. [11] showed approximate equivalence in terms of adverse event rates with ACL/FOR versus SFC, except for a $1.9 \%$ incidence of pneumonia with the ICS (SFC) group compared with $0.6 \%$ for ACL/FOR. Although VogelmeIER et al. [11] measured TDI, CAT, and SGRQ, and intriguingly looked at all-day, daytime and night-time symptom questionnaires, the two treatment groups scored roughly equally, with either combination similarly benefitting PRO outcomes.

The "real world" approach of Vogelmeier et al. [11], utilising only an overnight washout of prior maintenance COPD medications at randomisation impaired the study's sensitivity to evaluate important end-points such as trough FEV1. Concomitant prior medications masked baseline data for PROs, salbutamol use and symptom scores since there was no true baseline period after withdrawing confounding therapies. Current LAMAs (tiotropium, umeclidinium, glycopyrrolate) and ultra-LABAs (indacaterol, vilanterol, olodaterol) all have effective half-lives approaching $24 \mathrm{~h}$ and accumulate airway effects over 7-10 days. Therefore an overnight washout of prior bronchodilators does not accurately discern baseline FEV1 (free of confounding medications). Other studies, including ILLUMINATE [5], LANTERN [8] and ENERGITO [7], prescribed the easy to wash-out short-acting muscarinic antagonist (SAMA) ipratropium dosed four times daily for all patients during a $\sim 2-4$ week run-in period to accurately determine baseline COPD FEV1 and stability levels. In this sense, "real world" studies are often scientifically compromised. Key end-points such as trough FEV1, which do show potential benefits for ICS should not routinely be confounded by concomitant medications.

So are there any COPD patients remaining who do consistently need ICS/LABA as their preferred therapy? Here the answer is certainly yes. At least three identifiable groups are likely to require ICS in their initial therapy to control COPD.

Many COPD patients (up to 20-30\%) may have asthma-like characteristics including frank atopy marked by overt allergies to dusts, moulds and pet dander, or by comorbid atopic diseases such as allergic rhinitis, atopic dermatitis or sinusitis marking Th2 immune over-activation. When such atopic patients smoke, they develop a mixed syndrome of COPD overlaid upon asthmatic inflammation. These asthma-COPD overlap syndrome (ACOS) patients almost certainly benefit from ICS, which critically limit the Th2 cellular inflammation driving the asthma component. GERSHON et al. [12] showed improvements in risk of death or hospitalisation for ICS/LABA treatment versus bronchodilator LABA alone in COPD patients with a past history of asthma. Since asthma is also ubiquitous and can be a subtle diagnosis, ICS/LABA combinations are likely to remain the predominant therapy for smoking patients with mixed risk from an atopic or asthmatic past history before 40 years of age, as well as in the broader asthma population.

High exacerbation risk COPD patients with $\geqslant 2$ exacerbations or one hospitalisation annually are also more likely to benefit from ICS. Frequent past exacerbations foretell future moderate-to-severe exacerbations, hospitalisations, and potential patient mortality rates [13]. Trials of the newest ICS/LABA, fluticasone furoate/ vilanterol, showed reductions in COPD exacerbations with the ICS/LABA versus mono-bronchodilators [14]. Importantly, the FLAME study [9] predominantly enrolled patients with one COPD exacerbation in the prior year, which did not select the GOLD C and D highest risk classes, marked by two or more annual exacerbations. Several studies currently underway (GSK 116855, NCT02164513 and Pearl PT010005 or NCT02465567) should help answer the role of ICS in these frequent exacerbation patients and provide additional head-to-head LAMA/LABA versus ICS/LABA comparisons in this high severity group. 
Thirdly, high blood eosinophils are emerging as a promising biomarker to identify patients benefiting from ICS or ICS/LABAs. While the FLAME study measured only a single baseline blood eosinophil test, more compelling data have emerged from other studies targeting eosinophilic inflammation with newer anti-interleukin (IL)-5 therapies targeting asthma or COPD such as mepolizumab, reslizumab and the IL-5 receptor blocker, benralizumab. Some $10-30 \%$ of COPD patients show elevated blood eosinophils. The cut-point of $2 \%$ cited in the FLAME study seems too low. Either blood eosinophils $>3-4 \%$ or $>200-$ 300 cells per high power field (independent of white cell count) represent better phenotypic markers for eosinophil predominant COPD $[15,16]$. ICS are highly likely to be effective in these populations since corticosteroids trigger apotosis and partial elimination of eosinophils, directly suppressing eosinophilic inflammation. Importantly, while the WISDOM study [17] first suggested most COPD patients could safely withdraw ICS therapy, a post hoc analysis by WATz et al. [18] showed WISDOM patients with high eosinophils $(>2-4 \%)$ did have significantly higher COPD exacerbation rates when ICS were withdrawn.

In summary, ACOS patients (and all asthma patients) as well as COPD patients with frequent exacerbations and high blood eosinophils are all likely to benefit from ongoing ICS/LABA therapies or from triple ICS/LABA+LAMA therapies for COPD.

Given the remaining high risk groups most in need of ICS therapy, I believe the time may be right to refine the paradigmatic GOLD classification and segregate the highest at-risk patients with frequent exacerbations, high eosinophils or with ACOS into a new COPD risk category: call it GOLD ("E") ("E" for eosinophils, exacerbations (and for ACOS)). The GOLD four-square diagram has befuddled primary care physicians and specialists for too long, by trying to compress an eight unit matrix into four squares: COPD patients are often poorly confined in these categories.

By elevating high exacerbation risk patients (and high eosinophil or ACOS patients) into a new GOLD "E" category, this also remedies the flawed mathematics of the GOLD A, B, C and D classes (figure 1).

(E) Frequent Exacerbations

( $\geqslant 2$ per year, $\geqslant 1$ hospitalisation)

High Eosinophils

( $\geqslant 3-4 \%$ or $\geqslant 200-300$ cells per high power field) ACOS

Initial treatment Alternative treatment

(Asthma age $\leqslant 40$ years, atopy $+\lg E$ tests)

(move up to next severity class)

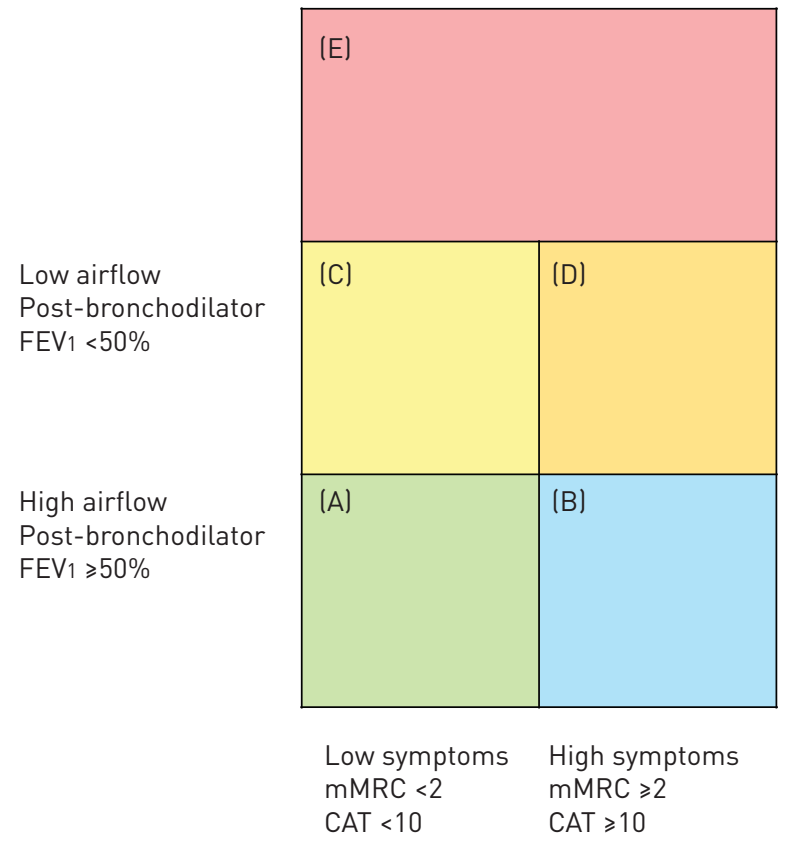

\begin{tabular}{|c|c|}
\hline $\begin{array}{l}\text { (E) Exacerbation-ICS therapy } \\
\text { ICS/LABA }\end{array}$ & $\begin{array}{l}\text { Exacerbation-triple } \\
\text { therapy } \\
\text { ICS/LABA+LAMA }\end{array}$ \\
\hline $\begin{array}{l}\text { (D) } \frac{\text { Combination-Dual }}{\text { bronchodilator }} \\
\text { LAMA/LABA }\end{array}$ & $\begin{array}{l}\text { Exacerbation-triple } \\
\text { therapy } \\
\text { ICS/LABA+LAMA }\end{array}$ \\
\hline 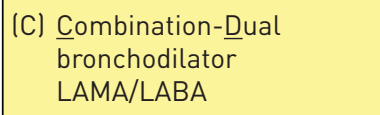 & $\begin{array}{l}\text { Exacerbation-triple } \\
\text { therapy } \\
\text { ICS/LABA+LAMA }\end{array}$ \\
\hline $\begin{array}{l}\text { (B) Bronchodilator } \\
\text { LAMA or LABA }\end{array}$ & $\begin{array}{l}\text { Combination-Dual } \\
\text { bronchodilator } \\
\text { LAMA/LABA }\end{array}$ \\
\hline $\begin{array}{l}\text { (A) As needed SABA, } \\
\text { SAMA or SAMA/SABA }\end{array}$ & $\begin{array}{l}\text { Bronchodilator } \\
\text { LAMA or LABA }\end{array}$ \\
\hline
\end{tabular}

All patients also utilise as needed SABA, SAMA, SAMA/SABA rescue therapy

FIGURE 1 Global Initiative for Chronic Obstructive Pulmonary Disease (GOLD) scheme revised to include class "E": for exacerbation risk, eosinophils, asthma-chronic obstructive pulmonary disease (COPD) overlap syndrome (ACOS). Categories A-D have been simplified and treatment recommendations progress $\mathrm{A}, \mathrm{B}, \mathrm{C}, \mathrm{D}$ and $\mathrm{E}$. FEV1: forced expiratory volume in $1 \mathrm{~s}$; mMRC: modified Medical Research Council; CAT: COPD Assessment Test; ICS: inhaled corticosteroid; LABA: long-acting beta-agonist; LAMA: long-acting muscarinic antagonist; SAMA: short-acting muscarinic antagonist; SABA: short-acting beta-agonist. 
Importantly, the putative "E" class specifically identifies patients who remain likely to benefit from ICS therapy (and ICS/LABAs).

Once "E" class patients are elevated above the lower classes A-D, this lets the GOLD four-square diagram really work to identify low and high symptomatic patients, and high and low airflow patients into GOLD classes A-D with no blurring or heterogeneity of groups. The majority of patients remaining in GOLD classes $\mathrm{B}, \mathrm{C}$ and $\mathrm{D}$ are likely to benefit from the newest LAMA/LABA therapies, rather than ICS/LABA.

Head-to-head studies $[5-9,11]$ show the LAMA/LABAs work especially well to boost airflow and improve rescue salbutamol use, which should help low airflow GOLD categories C and D. In a revised severity classification A-E, an initial treatment for GOLD A could recommend as needed short-acting bronchodilators (such as short-acting beta-agonist (SABA)), and initial treatment for GOLD B might utilise long-acting bronchodilator monotherapies. The combination-dual LAMA/LABAs are likely the best therapy in revised GOLD C and D low airflow patients, who may benefit most from the potent airflow improvement with several LAMA/LABAs.

In summary, recent data suggest clinicians may do well to add an "E" into the alchemy of COPD inhaled pharmacology. The Global Initiative for Obstructive Lung Diseases (and Exacerbations) "GOLDE" committee should strongly consider this expansion in their alphabet to appropriately identify and target patients who may benefit greatly from ICS/LABAs in a world increasingly rife with LABA/LAMAs.

\section{References}

1 Global Initiative for Chronic Obstructive Lung Disease (GOLD). Global Strategy for the Diagnosis, Management and Prevention of COPD, 2016. Available from: http://goldcopd.org/

2 Agusti A, Hurd S, Jones P, et al. FAQs about the GOLD 2011 assessment proposal of COPD: a comparative analysis of four different cohorts. Eur Respir J 2013; 42: 1391-1401.

3 D’Urzo A, Donohue JF, Kardos P, et al. A re-evaluation of the role of inhaled corticosteroids in the management of patients with chronic obstructive pulmonary disease. Expert Opin Pharmacother 2015; 16: 1845-1860.

4 Calverley PM, Anderson JA, Celli B, et al. Salmeterol and fluticasone propionate and survival in chronic obstructive pulmonary disease. N Engl J Med 2007; 356: 775-789.

5 Vogelmeier CF, Bateman ED, Pallante J, et al. Efficacy and safety of once-daily QVA149 compared with twice-daily salmeterol-fluticasone in patients with chronic obstructive pulmonary disease (ILLUMINATE): a randomised, double-blind, parallel group study. Lancet Respir Med 2013; 1: 51-60.

6 Donohue JF, Worsley S, Zhu CQ, et al. Improvements in lung function with umeclidinium/vilanterol versus fluticasone propionate/salmeterol in patients with moderate-to-severe COPD and infrequent exacerbations. Respir Med 2015; 109: 870-881.

7 Beeh KM, Derom E, Echave-Sustaeta J, et al. The lung function profile of once-daily tiotropium and olodaterol via Respimat $^{\circledR}$ is superior to that of twice-daily salmeterol and fluticasone propionate via Accuhaler ${ }^{\oplus}$ (ENERGITO study). Int J COPD 2016; 11: 193-205.

8 Zhong N, Wang C, Zhou X. LANTERN: a randomized study of QVA149 versus salmeterol/fluticasone combination in patients with COPD. Int J COPD 2015; 10: 1015-1026.

9 Wedzicha JA, Banerji D, Chapman KR, et al. Indacaterol-glycopyrronium versus salmeterol-fluticasone for COPD. N Engl J Med 2016; 374: 2222-2234.

10 Horita N, Goto A, Ota A, et al. Long-acting muscarinic antagonist plus long-acting beta agonist versus long-acting beta agonist plus inhaled corticosteroid for stable chronic obstructive pulmonary disease. Cochrane Database Syst Rev 2016; 2: CD012066.

11 Vogelmeier C, Paggiaro PL, Dorca J, et al. Efficacy and safety of aclidinium/formoterol versus salmeterol/ fluticasone: a phase 3 COPD study. Eur Respir J 2016; 48: 1030-1039.

12 Gershon AS, Campitelli MA, Croxford R, et al. Combination long-acting $\beta$-agonists and inhaled corticosteroids compared with long-acting $\beta$-agonists alone in older adults with chronic obstructive pulmonary disease. JAMA 2014; 312: 1114-1121.

13 Hurst JR, Vestbo J, Anzueto A, et al. Susceptibility to exacerbation in chronic obstructive pulmonary disease. N Engl J Med 2010; 363: 1128-1138.

14 Dransfield MT, Bourbeau J, Jones PW, et al. Once-daily inhaled fluticasone furoate and vilanterol versus vilanterol only for prevention of exacerbations of COPD: two replicate double-blind, parallel-group, randomised controlled trials. Lancet Respir Med 2013; 1: 210-223.

15 Pascoe S, Locantore N, Dransfield MT, et al. Blood eosinophil counts, exacerbations, and response to the addition of inhaled fluticasone furoate to vilanterol in patients with chronic obstructive pulmonary disease: a secondary analysis of data from two parallel randomised controlled trials. Lancet Respir Med 2015; 3: 435-442.

16 Pavord ID, Lettis S, Locantore N, et al. Blood eosinophils and inhaled corticosteroid/long-acting $\beta$-2 agonist efficacy in COPD. Thorax 2016; 71: 118-125.

17 Magnussen H, Disse B, Rodriguez-Roisin R, et al. Withdrawal of inhaled glucocorticoids and exacerbations of COPD. N Engl J Med 2014; 371: 1285-1294.

18 Watz H, Tetzlaff $\mathrm{K}$, Wouters EF, et al. Blood eosinophil count and exacerbations in severe chronic obstructive pulmonary disease after withdrawal of inhaled corticosteroids: a post-hoc analysis of the WISDOM trial. Lancet Respir Med 2016; 4: 390-398. 